\title{
Influences of three-dimensional printing to product innovation design thinking
}

\author{
Ling Liu*, Xu Wang and Ping Guo \\ Beijing City, Daxing District Xinghua Street (two) No. 1, Beijing Institute of Graphic Communication, Beijing, China \\ *E-mail: liuling@bigc.edu.cn
}

\begin{abstract}
The increasing demand of individuation brings new challenges to traditional product design. This paper studies and analyzes three-dimensional print technology promotes the future development of product innovation design. The advantages of 3D printing equipment can help creative products enterprises shorten product manufacturing period and make them powerful in competition.

Keywords: three-dimensional printing, product design, innovative thinking.
\end{abstract}

\section{Guidelines}

Along with the enrichment of physical goods and the development oftechnology, more and more customers demand individuation service. Enterprises establish their customization system one by one to satisfy customers and win the competition. In the design process, more attention has been paid to user's individuation factors. In other words, the increasing demand of individuation brings new challenges to traditional product design. Facing with new customer demand, it is possible to realize product custom design through three-dimensional printing. So far, researches on custom design using three-dimensional printing have gained extensive attention. Researching on creative products custom design technology has profound theoretical significance and practical value of the establishment of custom design platform which meets customers' demand.

\section{Characteristics of products innovation design thinking}

According to the once shaping principle, 3D printer can manufacture complex structures which are hard to process or even cannot be processed under traditional methods. This pushes the limitations of traditional manufacturing. 3D printer shortens the distance between ideas and products by manufacturing three-dimensional objects as long as the designers have ideas and turn them into three-dimensional data model[1]. Yan Yongnian, professor and doctoral supervisor of Tsinghua University, mentioned that the biggest effect of three-dimensional printer is to train and inspire young men's intelligence when he gave a report in the lecture hall of Zhong tian institute of technology.

To meet the customers' changing demand, product manufacturers need to transform their old pattern which production promotes sales into a new way which requires manufacturers to arrange production according to customer requirement. Realizing product innovation design and personalized customization can help manufacturers reduce product cost, improve product quality, shorten time to market and provide quality service[2]. So far, customization pattern, which means implementing individual mass production to meet customer's individualized needs, has been applied widely. Facing with new customer demand, it is possible to realize product custom design through threedimensional printing. This custom method is an interactive, authentic, seasonable method which enables customers to see custom outcome immediately and get satisfied product. Customers can also participate in the design at conceptual design phase.

\section{Influences of three-dimensional printing to product innovation design thinking}

Throughout the entire history, design has been playing an important role that makes life more efficient, advanced and interesting by applying technical innovation. Sometimes it plays the same role of art. Applying digital technology into producing also belongs to this traditional. For the same reason, 3D print has become a controversial topic in the design community. Some people regard it as an innovative technology as important as printing press and steam engine, while others consider that is too exaggerated. Hence it is the perfect time to evaluate the influence of three-dimensional printing to design and its future development.

Designers take more and more advantages of the progress of digital technology to manufacture products with complex geometric structure and elusive shape. As a result, an aesthetic pursuit of this kind of structure which as if comes from other worlds will become more and more common. Designers no longer pursue to control the final form of 
their product, they prefer to design a method which enables others personalize the production. The reasons come from aspects of style as well as function. Amputees can build a complete suitable artificial lime using 3D print and arthritics can adjust kitchen wares' hand shank for an easy use.

3D printer can not only build new objects but copy existing ones in case of lost and damage as well. Therefore, designers must consider the interchangeability of individual part when they design original items. Meanwhile, the growing requirement of maintenance brings a new challenge to the design of a new business model.

Firstly, conceptual model: at early stage of design flow, using 3D print technology structure models can examine the construction, shape and functions of an object. Any defects can be modified at the first time. After this, if it needs, the process of construction, examination and modification can be done again and again until the best conceptual model has been designed. Translate two dimensional design drawing into real objects can surely accelerate the development process of a product and reduce costs. In addition, three-dimensional objects can help designers make better decisions faster by presenting design preferably.

Secondly, function prototypes: designers can prove the rationality of their designs through manufacturing function prototypes. At the same time, they can test the performance and evaluate engineering strictly using three-dimensional objects. 3D print technology can shorten the time to market and maximize product performance.

Thirdly, finished products: 3D print technology has been a new fashion within the industry. The application fields are various including aviation enterprises, medical equipment manufacturers and small cars manufacturers. Using 3D print technology to replace traditional manufacturing process can save time and also reduce costs. What's more, 3D print technology breaks the limitations of traditional manufacturing process and enables designers to modify their design whenever there is a need. In this way, enterprises can exploit new markets of customized services or small amount application apparatus.

\section{Three-dimensional print technology promotes the future development of product innovation design}

\subsection{Shorten the design period using 3D print technology}

Digital production can not only change the relation between designers and users but also improve the cooperation between designers and producers. Ultimately, 3D printing equipment may spread every town, where local residents can acquire custom products or maintain existing products by themselves, just like their ancestors ask blacksmiths for forging products. Without question, enterprises which have technical experience have begun their preparation.

If this imagination comes true, designers no longer need to find producers who appreciate their designs. What they need to do is to make a prototype of their products and then sell them to consumers like entrepreneurs.

Producing products with complex shapes rapidly give a solution to the crazy ideas of designers. On the surface, 3D print can bring some changes temporarily. But if we connect it with some modern words like internet, cloud technology, open-source sharing

And big data, we can see a whole new connotation of the possibilities provided by $3 \mathrm{D}$ print. At this moment, 3D print becomes a key technology to subversion manufacturing industry. In aspect of production pattern, 3D can bring us changes of customization. Because of the affiliation dissociation between internet and manufacturing industry, clients are willing to design the product with manufacturers, which is feasible. Product manufacturing turns from patterned mass production into customization low-volume production, leading to some outcomes including the elimination of traditional industrial production line, the simplification of supply chain and even changes of world manufacturing economic distribution.

The longer a design cycle of one product is, the longer it takes to market, which means less potential profit of enterprise. Because of the importance to shorten time to market, enterprises have to shorten decision making time during the conceptual phase of a design. These decisions will decide most cost factors including material selection, manufacturing technology and designed life. 3D print technology can optimize design process and maximize potential profit for enterprises. There are many difficulties between an excellent idea and a successful product. When it comes to estimate an idea and decide whether it is worth to be invested, 3D print technology can help enterprises by shortening evaluation time and improving efficiency.

Design process which experienced prototype iterative optimization repeatedly can lower the risks of failure products effectively. Because that 3D printer can manufacture models which have excellent properties and can stand rigorous tests, it is much easier for designers to design. Models manufactured by 3D printer can help designers and engineers understand everything about potential products and decrease leftover problems.

\subsection{Customize products using 3D print technology}

The greatest advantage of 3D print is to expand the imaginary space of designers and develop their imagination and creativity[3]. Future equipment manufacturing industry will focus on personalized customization. 3D printer does not manufacture objects through incision or molds as traditional manufacturing machines. From physical objects by laying one by one expand the range of number concept in aspect of physics. 3D printer can manufacture cultural and creative products which demand accurate internal depressions or interlock shapes in physical world, which could develop huge 
design space. 3D print technology enables consumers customize products based on their requirements. Mass production will turn into mass customization. Current mass production method pursues to gain scale benefit through minimizing costs, detailing labor division and normalizing operation procedure. It cannot meet the customers' diversified demand any longer. The basic strategy of customization is to strengthen the standardization of inside structure of products in the manufacturing process and to increase the diversity of external structure which can be perceived by customers.

3D print will change our life tremendously in the future. This change, actually, has been taken its place for a long time. This revolution includes the invention of computers and the prosperity of internet. As said by Chris Anderson in Makers: New Industrial Revolution: In the process of manufacturing industry having a digital revolution, physical objects have become different designs on the screen which can be shared on line in forms of documents[4]. In the past several decades, factories and design studios experienced this transformation. Today, it happens on the clients' computers as well as in their basements. From retail industry to publishing industry, once an industry shift to digital, it will go through profound revolution. The biggest change is who is manufacturing rather than how to do it. As long as the process can be done by computer, everyone can participate in it. This is the revolution which manufacturing industry is experiencing.

\section{Conclusion}

No matter what revolution occurs to the manufacturing industry because of the combination between internet and 3D print technology, the essence of industrial design remains unchanged. It is to solve and coordinate the relationship between people and objects. Products bring enjoyments to people not only in physical level but also spiritual level. No matter using traditional artisan craftsmanship or 3D print technology, the essence of design is to bring people a beautiful life. This is the fundamental which would not change forever.

$3 \mathrm{D}$ print technology provides a cost-effectiveness way to accomplish repeatedly design iteration. It can obtain immediate feedback information of product design on the critical initial phase of development process. 3D product technology can modify creative products immediately, which can help to reduce costs and shorten time to market. To enterprises which use 3D print technology in their design process, this gives them competitive advantages. Along with the decline of price, 3D printing equipment will enjoy a larger market share. The advantages of 3D printing equipment including speediness, precision and low-cost can help creative products enterprises shorten product manufacturing period and make them powerful in competition.

\section{References}

1. Y.G. Wang, X. Wang, Three-dimensional Printing, Beijing, Wuhan: Huazhong University of Science and Technology Press, (2013)

2. B. Evans, Analysis $3 D$ Printer: Science and Art of $3 D$ Printer, Beijing, China Machine Press, (2013)

3. H.Y. Wu, 3D Print: Three-dimensional Intelligent Digital Manufacturing, Electronic Industry Press, (2014)

4. C. Anderson, Makers: New Industrial Revolution, Beijing, China Citic Press, (2012) 